MIS junctions, and this possibility is also being studied.

This work was supported by NSF under contract number ECS-8308403. The support of a Mobile Foundation grant is also greatly appreciated.

'G. C. Salter and R. E. Thomas, Solid State Electron. 20, 95 (1977). ${ }^{2}$ P. Van Halen, R. P. Mertens, R. J. Van Overstraeten, R. E. Thomas, and J. Van Meerbergen, IEEE Trans. Electron Devices ED-25, 507 (1978).

${ }^{3}$ C. E. Norman and R. E. Thomas, IEEE Trans. Electron Devices ED-27, $731(1980)$.

${ }^{4}$ R. E. Thomas, R. B. North, and C. E. Norman, IEEE Electron Device Lett. EDL-1, 79 (1980).
${ }^{5} \mathrm{P}$. DeVisschere, IEEE Trans. Electron Devices ED-30, 840 (1983).

${ }^{6}$ K. H. Zaininger and A. G. Holmes-Siedle, RCA Rev. 28, 208 (1967).

${ }^{7}$ T-P. Ma, G. Scoggan, and R. Leone, Appl. Phys. Lett. 27, 61 (1975)

${ }^{8}$ T-P. Ma, Proc. 4th Int'l. Symposium on Silicon Mater. Sci. and Tech. 815, 427 (1981).

${ }^{9}$ M-R. Chin and T-P. Ma, Appl. Phys. Lett. 42, 883 (1983).

"V. Zekeriya and T-P. Ma (unpublished).

"Supplied by Emulsitone Co., 19 Leslie Court, Whippany, New Jersey 07981.

${ }^{12}$ C-A. Pan and T-P. Ma, Appl. Phys. Lett. 37, 163 (1980).

${ }^{13}$ C-A. Pan and T-P. Ma, J. Electrochem. Soc. 128, 1953 (1981).

${ }^{14}$ Private communication, Takashi Tamagawa and Amy Wong, Yale University, Department of Electrical Engineering.

${ }^{15}$ M-R. Chin and T-P. Ma, J. Appl. Phys. 53, 3673 (1982).

\title{
Silicon nitride films deposited with an electron beam created plasma
}

\author{
D. C. Bishop, K. A. Emery, J. J. Rocca, L. R. Thompson, H. Zarnani, and G. J. Collins \\ Department of Electrical Engineering, Colorado State University, Fort Collins, Colorado 80523
}

(Received 16 November 1983; accepted for publication 5 January 1984)

\begin{abstract}
Silicon nitride films have been deposited using an electron beam created plasma in a silane, ammonia, and nitrogen mixture. The films were deposited at substrate temperatures between 50 and $400^{\circ} \mathrm{C}$. Physical, chemical, and electrical properties of these films are reported.
\end{abstract}

PACS numbers: 81.15.Gh, 68.60. + q, 78.65.Jd, 73.60.Fw

Recently, ${ }^{1}$ we have demonstrated electron beam assisted chemical vapor deposition (EBCVD) of $\mathrm{SiO}_{2}$ films at low substrate temperatures $\left(150-400^{\circ} \mathrm{C}\right)$. The electron beam created plasma is spatially localized and has a unique electron energy distribution. ${ }^{2}$ Dissociation of the gaseous reactants occurs primarily in a $0.3-\mathrm{cm}$-thick by 2.5 -cm-wide strip located a few millimeters above the substrate as described previously. ${ }^{1}$ A side view of the electron beam created plasma in a silane, nitrogen, and ammonia atmosphere at 0.35 Torr is shown in Fig. 1. This planar dissociation region, defined by the electron beam geometry, provides an extended flux of reactant species and dissociation products which contributes to conformal coverage of irregular features. This occurs because the localized plane source appears infinite in extent compared to characteristic features on the substrate. More-

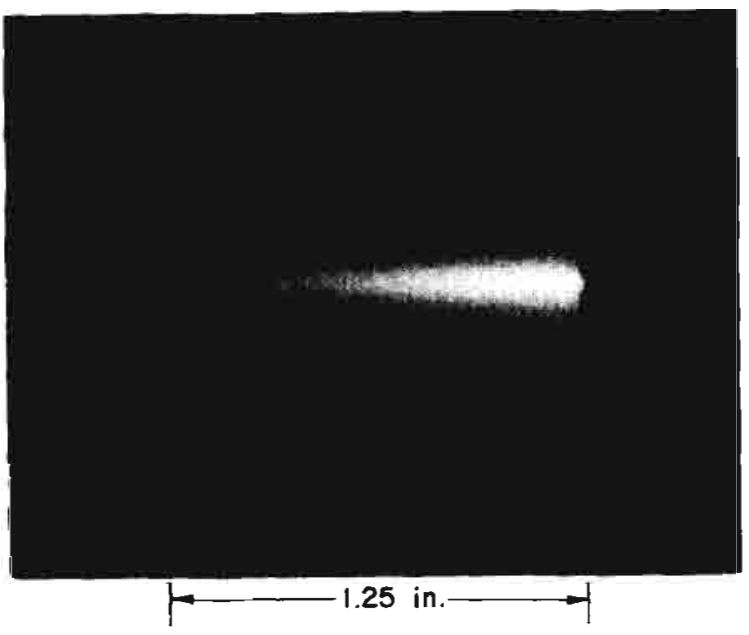

FIG. 1. Side view of the spatially confined electron beam created plasma. over, the confined excitation region helps to minimize gas phase generation of particulates and provides efficient use of the gaseous reactants.

Herein we describe the EBCVD of silicon nitride films using $\mathrm{NH}_{3}, \mathrm{~N}_{2}$, and $\mathrm{SiH}_{4}$ as the reactant gases. The silane source is $5 \% \mathrm{SiH}_{4}$ diluted in $\mathrm{N}_{2}$. Nitride films have been deposited on aluminum, $\mathrm{SiO}_{2}$, and polysilicon films as well as on crystalline silicon substrates. The wide range of experimental conditions under which EBCVD silicon nitrides have been deposited includes substrate temperatures, from 50 to $400{ }^{\circ} \mathrm{C}$, electron beam current values from 2 to $40 \mathrm{~mA}$, electron beam energies from 1 to $5 \mathrm{keV}$, total ambient pressures between 0.1 and 0.4 Torr, and $\mathrm{NH}_{3} / \mathrm{SiH}_{4}$ mass flow ratios from 1 to 80 . The dependence of the deposition rate with electron beam current, gas pressure, and flow rates is

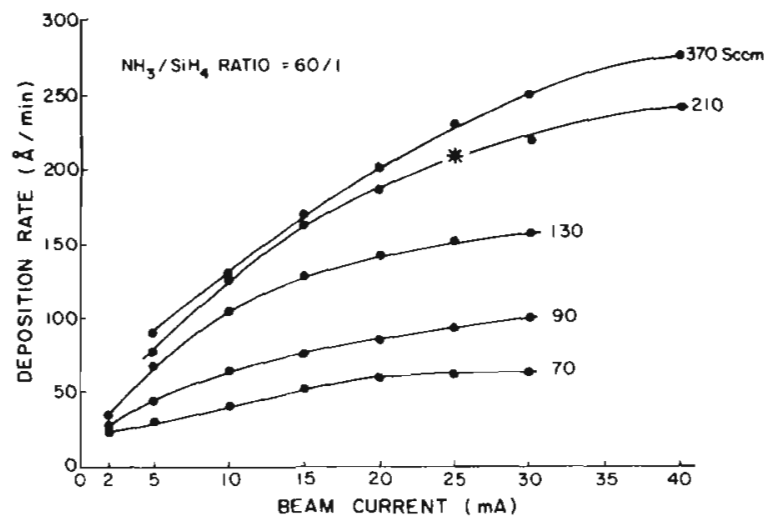

FIG. 2. Deposition rate vs beam current for varying total gas flow $\left(\mathrm{NH}_{3}+\mathrm{N}_{2}+\mathrm{SiH}_{4}\right)$ at a constant pressure of $0.35 \mathrm{Torr}$, and substrate temperature of $350^{\circ} \mathrm{C}$. The asterisk denotes the typical deposition conditions described in the text. 


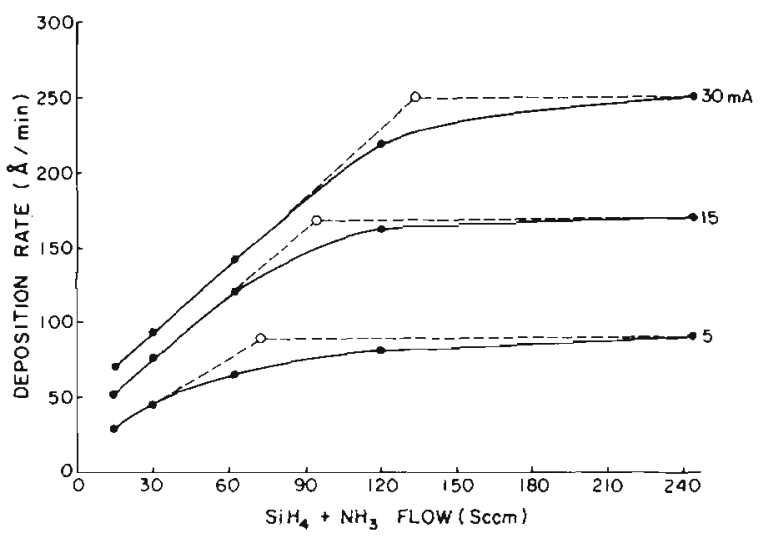

FIG. 3. Deposition rate vs silane plus ammonia flow for electron beam currents of 5,15 , and $30 \mathrm{~mA}$, at a total pressure of 0.35 Torr and a substrate temperature of $350^{\circ} \mathrm{C}$.

summarized in Figs. 2-4. Figure 2 illustrates the effect of varying the total flow rates, while holding the flow ratio of $\mathrm{NH}_{3}$ to $\mathrm{SiH}_{4}$ at 60 . The total cell pressure was held at 0.35 Torr by a downstream pump throttle valve. The deposition rate increases with both electron beam current and flow rates. However, the deposition rate rapidly saturates at low beam currents $(10 \mathrm{~mA})$. The deposition rate at fixed beam current increases with increasing gas flow as shown in Fig. 2. Figure 3 shows the deposition rate as a function of the total gas flow, for different electron beam current. Notice that for a given electron beam current the deposition rate saturates with increasing gas flow. The flow value at which saturation occurs increases with increasing current as shown by the intersection of the broken lines in Fig. 3. This effect is possibly due to depletion of the gas donors. Figure 4 illustrates the effect of varying total gas pressure from 0.2 to 0.4 Torr. The curves indicate that higher gas densities lead to higher deposition rates. Again the deposition rate saturates as the electron beam current increases.

The properties of the EBCVD $\mathrm{Si}_{3} \mathrm{~N}_{4}$ films, summarized in Table I, correspond to the following conditions: substrate temperature of $350^{\circ} \mathrm{C}$, total cell pressure of 0.35 Torr, and $\mathrm{NH}_{3}, \mathrm{SiH}_{4}$, and $\mathrm{N}_{2}$ flow rates of 120,2 , and $88 \mathrm{sccm}$, respectively. The electron beam current is $25 \mathrm{~mA}$ and the beam voltage is $4.2 \mathrm{kV}$. The conditions described above are indicated by an asterisk in Fig. 2.

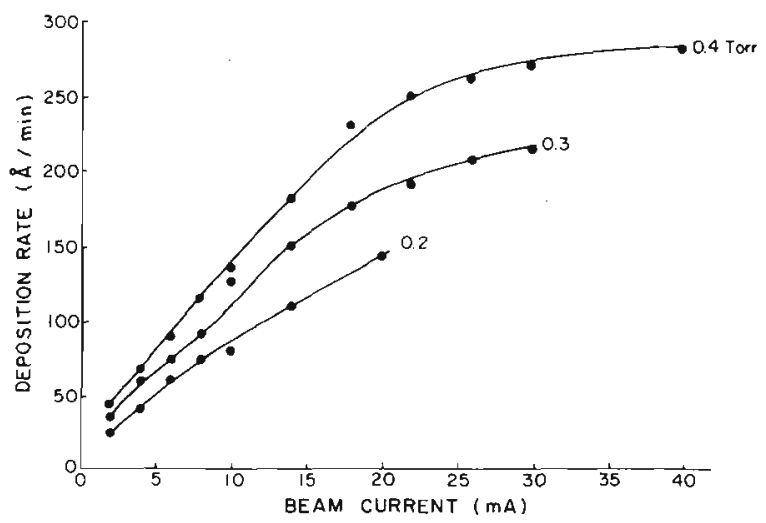

FIG. 4. Deposition rate vs beam current for pressures of $0.2,0.3$, and 0.4 Torr at a constant flow of $97.5 \mathrm{sccm} \mathrm{N}, 150 \mathrm{sccm} \mathrm{NH}$, and $2.5 \mathrm{sccm} \mathrm{SiH}_{4}$, and a substrate temperature of $400^{\circ} \mathrm{C}$.
TABLE I. Properties of electron beam deposited silicon nitride.

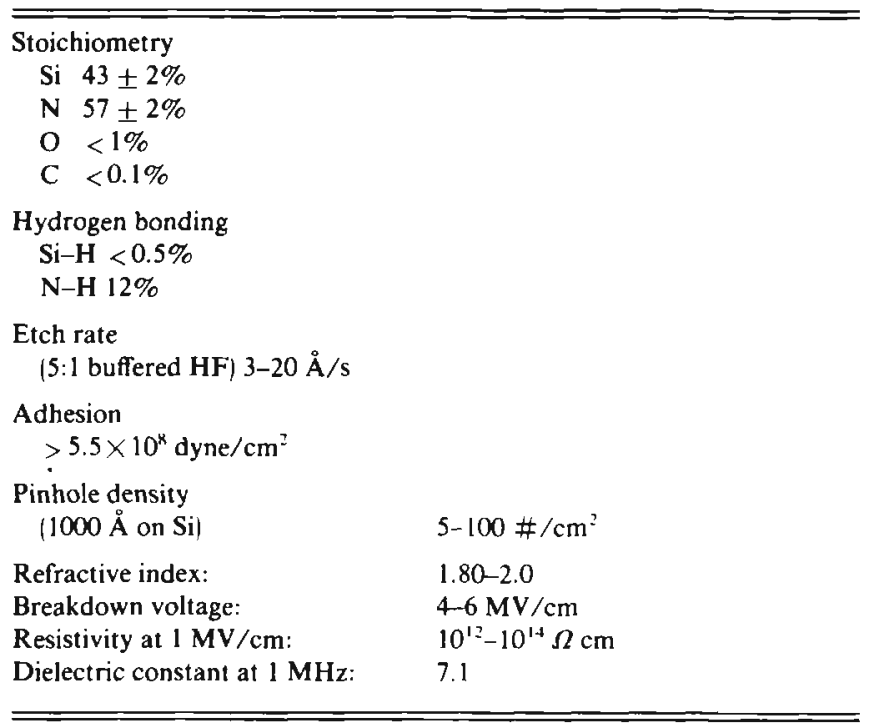

Auger measurements taken on the EBCVD $\mathrm{Si}_{3} \mathrm{~N}_{4}$ samples with $\mathrm{NH}_{3} / \mathrm{SiH}_{4}$ ratios from 1 to 80 are shown in Fig. 5 . The films are stoichiometric for $\mathrm{NH}_{3} / \mathrm{SiH}_{4}$ flow ratios greater than 5. A similar dependence of stoichiometry on flow ratios is observed with conventional plasma enhanced CVD. ${ }^{3,4}$ The amounts of oxygen and carbon incorporated in the films were below the detectability limits of sputtered Auger analysis $(0.1 \%)$. Several spatial locations were evaluated on each sample and the Auger data were taken during sputtering to reduce uncertainties from background oxygen reacting with the sputtered surface. Quantitative information on the $\mathrm{Si}$ and $\mathrm{N}$ content was achieved by comparing the $\mathrm{Si}(\mathrm{LMM})$ and $\mathrm{N}(\mathrm{KLL})$ Auger spectra of a $\mathrm{Si}_{3} \mathrm{~N}_{4}$ standard $^{5}$ and the EBCVD Si${ }_{3} \mathrm{~N}_{4}$ films. Auger measurements on the asdeposited surface show only $\mathrm{Si}_{3} \mathrm{~N}_{4}$ and no elemental silicon, indicating that all of the silane radicals reacted with ammonia forming $\mathrm{Si}_{3} \mathrm{~N}_{4}$ with $\mathrm{N}-\mathrm{H}$ bonding.

The $\mathrm{N}-\mathrm{H}\left(3340,1170 \mathrm{~cm}^{-1}\right)$ bond density for the $\mathrm{Si}_{3} \mathrm{~N}_{4}$ films was obtained by using IR transmission spectroscopy (integrated baseline tangent method $1 .{ }^{6} \mathrm{~A} k$ value of $8.2 \times 10^{16}$ $\mathrm{cm}^{-1}$, at $3340 \mathrm{~cm}^{-1}$ as suggested by Adams ${ }^{\hbar}$ for PECVD $\mathrm{Si}_{3} \mathrm{~N}_{4}$ films, was used. The $\mathrm{N}-\mathrm{H}$ bond density, assuming a film density of $2.7 \mathrm{gm} / \mathrm{cm}^{3}$, was calculated to be $12 \%$. There was no detectable $\mathrm{Si}-\mathrm{H}$ bonding $(<0.5 \%)$ in the films over a wide range of deposition conditions. The current versus voltage and capacitance versus voltage properties of the

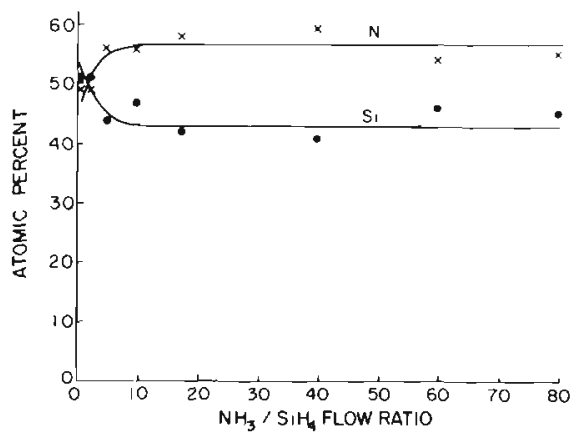

FIG. 5. A tomic percent of $\mathrm{Si}$ and $\mathrm{N}$ vs $\mathrm{NH}_{3}$ to $\mathrm{SiH}_{4}$ flow ratio with a total pressure of $0.3 \mathrm{Torr}$ and a substrate temperature of $350^{\circ} \mathrm{C}$. 


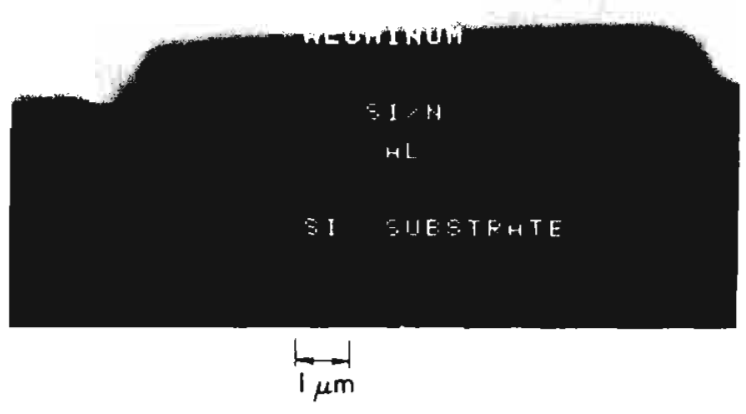

FIG. 6. SEM micrograph of EBCVD $\mathrm{Si}_{3} \mathrm{~N}_{4}$ covered by $\mathrm{Al}$ and conformally covering a $0.8-\mu \mathrm{m}$-high step. Deposition conditions include substrate temperature $350^{\circ} \mathrm{C}$, total pressure of $0.35 \mathrm{Torr}, \mathrm{NH}_{3}, \mathrm{SiH}_{4}$, and $\mathrm{N}_{2}$ gas flows of 120,2 , and $88 \mathrm{sccm}$, respectively.

EBCVD $\mathrm{Si}_{3} \mathrm{~N}_{4}$ films were measured on $\mathrm{Al} / \mathrm{Si}_{3} \mathrm{~N}_{4} / \mathrm{Si} / \mathrm{Al}$ structures. From current versus voltage analysis, the current conduction mechanism for the $\mathrm{Si}_{3} \mathrm{~N}_{4}$ films followed the Frenkel-Poole dependence. This behavior is typical of silicon nitride films and characteristic of field-enhanced charge emission from trapping centers. ${ }^{4.7}$

We have also studied the step coverage properties of the EBCVD technique. ${ }^{8}$ No film cracking has been observed in all scanning electron microscope (SEM) micrographs taken of the $\mathrm{Si}_{3} \mathbf{N}_{4}$ films, however, a slight cusping at the base of the step has been observed. Figure 6 illustrates a $0.9-\mu \mathrm{m}$-thick
EBCVD $\mathrm{Si}_{3} \mathbf{N}_{4}$ film deposited as an interlayer dielectric between a $0.8-\mu \mathrm{m}$-thick patterned aluminum step and a 0.7 $\mu \mathrm{m}$-thick aluminum film. The aluminum was sputter deposited and patterned using conventional photolithographic processing. A selective aluminum etch was then used to distinguish the $\mathrm{Si}_{3} \mathrm{~N}_{4} / \mathrm{Al}$ interfaces.

In summary, we have deposited stoichiometric, device quality silicon nitride films using a glow discharge electron gun.

This work was supported by NASA-Lewis (Joe Warner, Dave Liu) and the National Science Foundation. We thank Bill Ritchie, of NCR Microelectronics, Fort Collins, for pinhole density measurements and Lou Gobis, of $\mathrm{H}$. P., Loveland, CO, for providing silicon wafers and SEM photographs. We would also like to thank Tom Massapaust at the Solar Energy Research Institute for Auger measurements.

'L. R. Thompson, J. J. Rocca, K. Emery, P. K. Boyer, and G. J. Collins, Appl. Phys. Lett. 43, 777 (1983).

${ }^{2}$ Z. Yu, J. J. Rocca, G. J. Collins, and C. Y. She, Phys. Lett. A 96, 125 (1983) ${ }^{3}$ H. E. Maes, G. Heynes, J. Remmerie, H. Hinoul, H. Loos, A. Van Calster, A. Lequesne, and K. Allaert, Proceedings 1983 Meeting Electrochemical Society-Compound Semiconductors-Plasma Nitrides, San Francisco, CA, May 8-13, 1983.

${ }^{4}$ H. J. Stein, V. A. Wells, and R. E. Hampy, J. Electrochem. Soc. Solid State Sci. Technol. 126, 1750 (1979).

SThe Silicon Nitridge Auger Standard was purchased from C. M. Taylor Co. in Sunnyvale, California.

'A. C. Adams, Solid State Technol. 26, 135 (1983).

'S. M. Sze, Physics of Semiconductor Devices (Wiley, New York, 1981).

${ }^{8}$ L. R. Thompson, L. Gobis, D. Bishop, J. J. Rocca, K. Emery, and G. J.

Collins, J. Electrochem. Soc. Solid State Technol. 131, 462 (1984).

\title{
High-rate deposition of amorphous hydrogenated silicon from a $\mathrm{SiH}_{4}$ plasma
}

\author{
T. Hamasaki, M. Ueda, A. Chayahara, M. Hirose, and Y. Osaka \\ Department of Electrical Engineering, Hiroshima University, Higashihiroshima 724, Japan
}

(Received 11 October 1983; accepted for publication 3 January 1984)

An extremely high deposition rate of amorphous hydrogenated silicon has been achieved by employing a new $\mathrm{rf}$ discharge technique. The deposition rate has been increased to more than 50 $\AA / \mathrm{s}$ at a substrate temperature of $200^{\circ} \mathrm{C}$ without accompanying any appreciable deterioration in the electronic and structural properties as compared to those of specimens prepared at a conventional deposition rate $(\sim 1 \AA / \mathrm{A})$. Thermal stability of the high-rate samples is improved with respect to that of low-rate specimens.

PACS numbers: $81.15 .-z, 68.55 .+b, 73.60 . F w, 68.60 .+q$

Recent developments in technological applications of discharge-produced amorphous hydrogenated silicon $(a-$ $\mathrm{Si}: \mathrm{H})$ to photoreceptors and low-cost solar cells raise a strong demand for realizing high-rate deposition. The deposition rate from a $\mathrm{SiH}_{4}$ plasma is increased by increasing the rf power density and the concentration of a $\mathrm{SiH}_{4}$ feed gas as well. ${ }^{1}$ However, the growth rate has been limited typically in the range of $1-5 \AA / \mathrm{s}$ because an increase in the deposition rate results in silicon flake formation in the gas phase and in deterioration of film properties. ${ }^{2}$ The optimum growth of high quality $a-\mathrm{Si}: \mathrm{H}$ appears to take place through the heterogeneous reactions of adsorbed chemical species on the substrate surface. ${ }^{3}$ Therefore, to achieve high-rate deposition it is necessary to enhance the concentration of reactive species near the substrate surface and to suppress the gas phase polymerization reactions which lead to silicon flake formation. 